\title{
Developing a Laboratory for Engineering Education in Mechatronics
}

Alireza Fazlirad and Robert W. Brennan

Schulich School of Engineering, University of Calgary
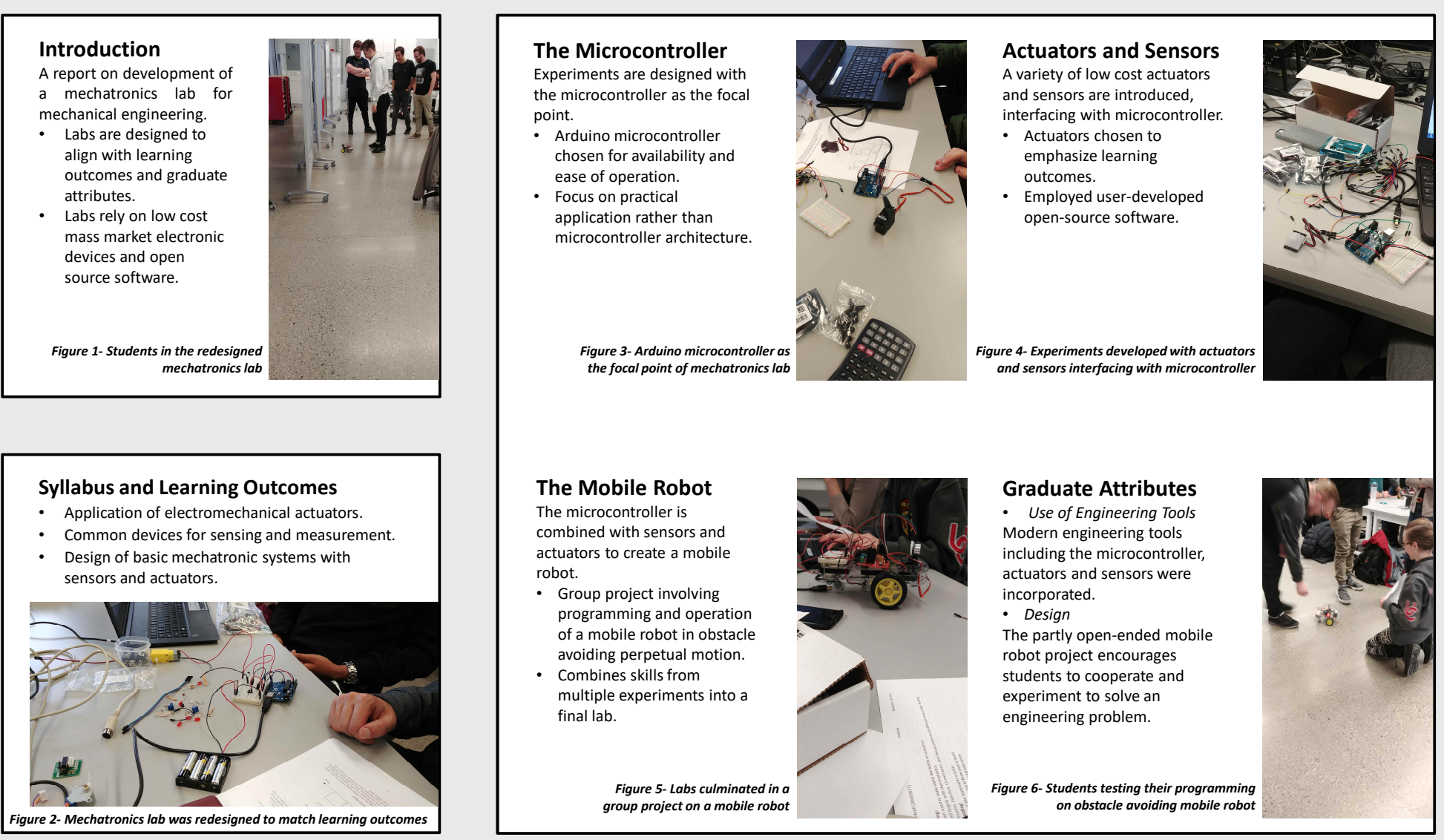

\section{Student Feedback}

Labs were met with universal student approval,

feedback included:

- "Very fun and practical applications."

- "Labs were challenging but very useful."

- "Lab is really interesting. Doesn't happen often

enough.

- "Lab is cool and interesting."

"The labs were somewhat challenging but really

interesting and beneficial."

"I enjoyed the labs a lot it was fun to learn about micro processors."

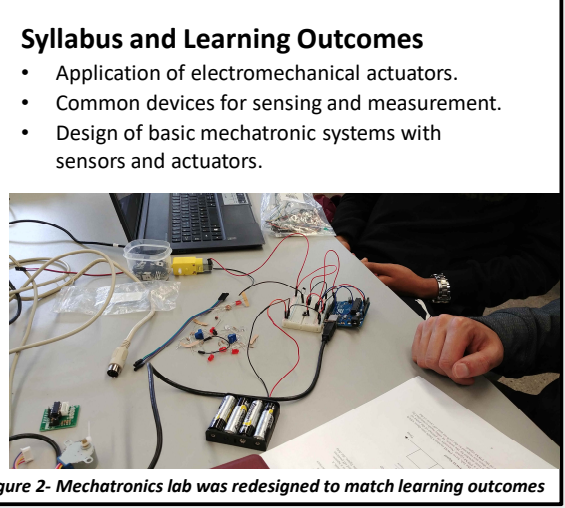

The Mobile Robot The microcontroller is

mbined with sensors and

oup project involvin

xperiments into (n)
Challenges and limitations

- Low-cost devices pose reliability issues.

Arduino IDE is simple to use, but not sufficient for industrial practice.

Open-source software availability discourages discovery.

Dedicated data acquisition hardware

advantageous.

Assessment of project-based labs can be

improved.

Time, prerequisite student skills are limiting factors.

\section{Literature cited}

R. V. Krivickas and J. Krivickas, "Laboratory Instruction in Engineering Education," Global Journal for Engineering Education, vol. 11, no. 2, pp. 191-196, 2007.

L. D. Feisel and A. J. Rosa, "The Role of the Laboratory in Undergraduate Engineering Education," Journal of Engineering Education, pp. 121-130, 2005.
Canadian Engineering Accreditation Board, "Accreditation Criteria and Procedures Report, Engineers Canada, 2017.

S. Ahmed, S. Imtiaz, L. James and D. Spracklin-Reid, "Designing Laboratory Procedures to Enhance Graduate Attributes," in Proceedings of 2013 Canadian Engineering Education Association (CEEA13) Conference, Montreal, 2013

\section{Acknowledgments}

Support from the National Science and Engineering Research Council of Canada is gratefully

acknowledged.

uthors wish to thank graduate teaching assistants Alex Li and Jaime Garcia Rodriguez.
Further information

afazlira@ucalgary.ca 